\title{
Information Technology Support for Communities of Practice: How Public Defenders Learn about Winning and Losing in Court
}

\author{
Noriko Hara \\ Rob Kling Center for Social Informatics \\ School of Library and Information Science \\ Indiana University \\ 10th \& Jordan, Indiana University \\ Bloomington, IN 47405 USA
}

Heading: IT Support for CoPs

Acknowledgements: This study was made possible with the help of the Circle County Public Defender's Office. Blaise Cronin, Bradley Levinson, Rob Kling, Tom Schwen, and anonymous reviewers provided helpful insights and comments.

This is a preprint of an article accepted for publication in the Journal of American Society for Information Science \& Technology, 58(1), 76-87. @2007 Wiley.

Please do not quote from this version as it may be different from the published version. 


\begin{abstract}
The aim of this article is to examine the role of information technologies (IT) in supporting practice and professional identity formation, both major axes for communities of practice. The article uses an ethnographic case study to understand how public defenders learn to improve their court performance. The concept of "communities of practice” helps to illuminate how the attorneys in a public defender's office share knowledge in order to practice effectively in court. This article presents findings that a community of practice serves as effective scaffolding to support professional development; this is especially true for the practice component. Further, this case study indicates that information technologies, such as listservs, are not very effective social integrators for professionals who work at different sites. In particular, today's IT forums are most effective when used for sharing technical information about work, and least effective for sharing important cultural meanings about how professionals should approach their work and develop professional identities. This research advances our understanding about the complexity of organizing communities of practice to support professional groups of colleagues and IT-enabled support for various activities.
\end{abstract}

\title{
Introduction
}

Information Technology (IT) research scholars use IT to attempt to improve the efficiency of group work. Some researchers focus primarily on time and money as measures of efficiency. For example, IT can connect people in dispersed locations, and that can save travel time and be economical, but actual collaboration may not work well without face-to-face communication (Olson \& Olson, 2001). Other researchers have been developing information technologies that improve the effectiveness of teamwork and organizations (e.g., Cohen \& Bailey, 1997; DeSanctis \& Poole, 1997; Jarvenpaa \& Liedner, 1999). Researchers working in the late 1990s recognized the importance of knowledge sharing as a key to fostering learning within organizations or occupational communities (Brown \& Duguid, 1996, 2000). 
The present study examines the use of Information Technologies in such communities of practice. Ethnographers have a longstanding tradition of studying occupational communities (Orr, 1990; Van Maanen \& Barley, 1984). While some authors claim that IT has the potential to support online communities of practice (e.g., Sharp, 1997; Kim, 2000), few detailed empirical studies have been conducted.

The research question asked in this article is: what roles can IT play in supporting different types of communities of practice—both practice and identity? This article’s analysis is based on a case study conducted at a public defender's office using an ethnographic method. The article explores the use of IT to achieve work efficiency and to foster professional identities. In addition, a modified social action framework is proposed (Ngwenyama \& Lyytinen, 1997).

\section{Communities of Practice}

The concept of communities of practice was developed by Lave and Wenger (1991). The term has since been popularized by Brown and Duguid (1996) following their analysis of Orr’s ethnographic study at Xerox (see Orr 1990, 1996). More recently, this term has become well-known in the corporate world (e.g., Brown \& Duguid, 2000; Krackhardt \& Hanson, 1993; Ruhleder, Jordan, \& Elmes, 1996; Stewart, 1996; Wenger, 2000; Wenger, McDermott, Snyder, 2002), and many companies have tried to design communities of practice to improve knowledge sharing within their organizations.

Because the use of the term, communities of practice, is elusive among different scholars, the following definition is used in this paper: "Communities of practice are informal networks that support professional practitioners to develop a shared meaning and engage in knowledge building among the members" (Hara, 2000, p. 11). This definition is based on Wenger's four traits that define communities of practice as a social way of learning: 
negotiating meaning; preserving and creating knowledge; spreading information; and being a home for identities (Wenger, 1998).

Whereas the term "communities of practice" has a seemingly romantic connotation of individuals sharing knowledge with others, such sharing requires complex coordination to implement. Ekbia and Hara (in press) discuss the difficulty of situations known as social dilemmas — namely, those interactions where individuals act rationally (trying to maximize individual gain) but their rational acts lead to collective irrationality (Kollock 1998; c.f., Cabrera \& Cabrera 2002). It has been suggested that knowledge sharing can be understood as a special instance of a social dilemma (Connolly, Thorn, \& Heminger 1992; Cabrera \& Cabrera 2002). Kling and Courtright (2004) address the issue of trust that prevented teachers from actively participating in a community of practice. In a similar vein, O’Leary, Orlikowski, and Yates (2002), in their historical analysis of Hudson’s Bay Company, describe individuals' need for balancing trust with control in group dynamics.

Huysman (2005) contends that there are three traps for knowledge sharing: the management trap, the individual learning trap, and the information and communication technology trap. She contends that top-down knowledge management strategies are likely to fail. George, Iacono, and Kling (1995) describe a case of implementing a new IT project with a top-down strategy as an ineffective way of learning; they contrast this method with a more effective learning process, a grassroots initiative, in which a group of professionals learned from each other through informal learning within their community of practice. In Husman's view (2005), traditional means for supporting individual learning, such as classroom training and database searching, are difficult to transform into 
a socially shared process. Finally, Huysman states that some types of tacit knowledge are difficult to share by means of information technologies. Swan, Robertson, and Newell (2002) raise similar concerns regarding IT-based knowledge management. Schwen and Hara (2004) take the position that communities of practice emerge; they are seldom artificially developed.

Communities of practice consist of two major axes—practice and identity (Wenger, 1998). It is natural that practice is a core component of a community of practice because a community of practice forms around a certain practice, such as legal practice, medical practice, library practice, teaching practice, etc. On the other hand, the identity component is not very intuitive. If practice is a core component of a community of practice, identity serves as the glue that connects members of the community. Identity is an underlying philosophy that serves to attract and retain members to a community. However, more attention is paid to the role of informal learning when communities of practice are discussed in the past (Johnson, 2001) because communities of practice provide environments for fostering informal learning; thus, not much attention to identity information. In the original definition, Lave and Wenger emphasized "legitimate peripheral participation" that is a form of apprenticeship and allows newcomers to participate at the edge of their community and learn the lingo and identity to eventually become full members of the community. Nevertheless, the apprentice learning aspect has been taken notice, and the identity development aspect attracts little interest, within the framework of communities of practice. This tendency may have been instigated by the fact that the community of practice framework fit knowledge management (e.g., Brown \& Duguid, 2000; Wenger, 2000). Thus, learning and knowledge sharing have been 
highlighted while identity has received less notice. Wenger (1998) himself also contends that legitimate peripheral learning was the emphasis in his previous work with Lave and that not enough attention was paid to the concept of identity and community of practice.

\section{Professional Socialization and Identity}

One of the roles that communities of practice plays is to provide a milieu for professional socialization in order to build professional identity. Having colleagues with whom to exchange ideas is an important part of being a member of a community of practice (Singer, 1982; Weedman, 1999). Su (1992), who argues the importance of mentoring and socialization for preservice teachers, also reports that preservice teachers find informal interactions—such as meeting with professors for meals, retreats, week-end gatherings - to be vital, because they gain more useful information as a result of informal talks and discussions than they do from seminars. His finding is consistent with earlier studies (e.g., Parsons, 1939), as well as with Brown and Duguid's assertion (1996) about the importance of informal learning. The following summaries this point: "Everyday practice is a more powerful source of socialization than intentional pedagogy” (Lave, 1988, p. 14).

Singer (1982) argues the significance of developing one's self within the professional community. He also notes that, although book knowledge is provided, most training programs do not assist students with understanding the roles of professionals in the real world. Singer further claims that participants need socialization in order to learn the professional identity of a particular profession. "Socialization is a mutually influential process" (Su, 1992, p. 247) for many professionals, including public 
defenders, high-energy physicists (Traweek, 1988), librarians (Davenport, 2001), and teachers (Su, 1992).

Of course, individuals can and should develop their own identities. Eisenhart (1995) and Holland (1992) studied the relationships between individual identities and group identity and examined how these influenced each other. Holland reported how college female students who were originally interested in science and mathematics changed their career directions to pursue romance and look for husbands because of peer pressure. Eisenhart discussed the interaction between individual identities and organizational identity and how these influenced each other. Individuals also negotiate their identities as members of a community through their engagement with communities of practice (Wenger, 1998).

In this article, the researcher will discuss how IT may or may not support practice and identity development that are both major components of communities of practice.

\section{Research Approach}

\section{Data Collection}

The researcher selected an ethnographic case study methodology in order to develop rich descriptions of communities of practice. It is important to reveal the inside of the "black box"” (Latour, 1999), and using an ethnographic methodology is an appropriate approach for this purpose. The researcher obtained permission for access to a

\footnotetext{
${ }^{1}$ When technology or science works well, people tend to ignore the mechanics by which the system operates. This is called blackboxing because people are inclined to pay attention to input and output, but ignore the complexity of the actual process, i.e., the system operation might as well take place inside of an opaque box.
} 
public defender's office located in a large city in Circle County ${ }^{2}$ and conducted an ethnographic study.

The public defender's office was the largest public defender's office in the state and, at the time of the study, employed approximately 50 full-time attorneys, 60 part-time contract attorneys, and 50 support staff. The office dealt with approximately 32,000 cases in 1998. The researcher used observations, interviews, and document reviews for data collection.

Observations. Observations were conducted in the public defender's office in Circle County between July and October of 1999. These sessions included observations of the office during interviews, informal lunch meetings, an office picnic, a criminal bar association meeting, a management retreat, and the shadowing of two attorneys during workdays. The researcher made frequent use of opportunities to informally observe the office and the attorneys in the office.

Interviews. Interviews, focusing on the attorneys' work practices and their use of information technologies to support their practices, were conducted individually during office hours. Informants included the chief public defender, the training director, the resource coordinator, six misdemeanor/class D felony attorneys, seven major-felony attorneys, a contract part-time attorney, and the supervisors of both the misdemeanor/class D felony and the major felony divisions. ${ }^{3}$

\footnotetext{
${ }^{2}$ The identity of the location is disguised.

${ }^{3}$ The public defenders were separated into groups by specializations. The misdemeanor attorneys handle cases where the possible punishment is less than one year. Class $\mathrm{D}$ felonies refer to crimes punishable by up to three years in jail--including burglary, domestic violence, and driving while intoxicated. The "major felonies" have penalties that exceed three years. These distinctions will be examined in detail later in the article.
} 
The six misdemeanor/D felony attorneys interviewed were selected by a training director from among twenty-three to twenty-four attorneys ${ }^{4}$ in the misdemeanor/D felony division. The training director, who served as a contact person for this research, was a practicing major felony attorney; she sent out e-mail invitations to those misdemeanor/D felony attorneys who were not scheduled to go to court on the days of the researcher's site visits. In addition, the training director mentioned that she "might have" selected more technology-savvy attorneys because she knew that the research topic was related to IT. The major-felony attorneys were also contacted by the training director. However, this time she sent out e-mail invitations to all of the major felony attorneys because they did not have court days. Consequently, the training director received more volunteers than there were slots available for interviews. In this case, she selected the first six attorneys who replied. One additional major-felony attorney was selected by a secretary to the chief public defender during the researcher's initial visit to their office.

Each interview lasted between half-an-hour and forty-five minutes. All interviews were semi-structured (see the interview questions in Appendix A) and questions were changed according to the informants' answers. All formal interviews were tape-recorded and transcribed; the informants' names in the text are pseudonyms. In addition, informal conversations with other attorneys in the office took place throughout the fieldwork.

Document reviews. The researcher reviewed the office's Web site, an organization roster, and a printout of a portion of online discussions on a listserv, which was provided by the Public Defender Council. The Web site describes the mission of the

\footnotetext{
${ }^{4}$ During the fieldwork, one attorney quit. The interviews were conducted over two time periods. During the first, there were twenty-four attorneys; in the second period, there were twenty-three attorneys. The
} 
organization, general information about the office, the organizational structure, frequently asked questions for clients, and contact information for all the attorneys. In addition, some attorneys informally showed the researcher internal e-mail messages and the database system that they use in daily practice.

\section{Data Analysis}

"There is no particular moment when data analysis begins" (Stake, 1995, p.71). The data were analyzed holistically and indexed by categories, with major themes of the study presented in a final document. Three different kinds of data (observation, interview, and document review data) were analyzed simultaneously as they were collected. All written text (observation notes, researcher's reflection logs, interview transcriptions, and documents obtained) was coded after the fieldwork was conducted.

Throughout the coding process, themes noted during the fieldwork were confirmed and additional themes were found. Silverman (1996) suggests two forms of validation of qualitative research: triangulation and member-checking. In the present study, different types of triangulation were used—such as data source, collection method, time, and theory. Furthermore, the informants who participated in the study were asked to examine the researcher's observation vignettes and interview transcripts as well as interpretations of these data in order to check the materials for accuracy. In addition to individual validation of the interviews, the researcher asked the training director to provide feedback on the analysis. After each site visit, the initial analysis was e-mailed to the training director and validated with her. Similarly, the analysis was shared with the supervisor of the major-felony attorneys who was also asked to give feedback on the 
analysis. Feedback from the informants was obtained in order to establish the trustworthiness of the data (Lincoln \& Guba, 1985).

\section{IT Supports Practice in the Circle County Public Defender's Office}

The IT infrastructure in the Circle County public defender's office is much more sophisticated than in other public defender's offices in the state. Every attorney has had an office computer since 1995 or 1996. Currently, the office has a regular e-mail system, called Groupwise, and Internet access. The attorneys have access to a listserv that connects defense attorneys in this state. Each computer is connected to a Local Area Network (LAN), so that the attorneys have access to databases for criminal records and police reports available in Circle County. They also have access to legal-research tools, such as Lexis-Nexis and Premise, a product of WestLaw.

There are different roles that information technology can play in support of legal practice in the public defender's office. The organization does not have a master plan for using IT to connect these public defenders, but the researcher observed the way in which IT was used. The researcher used the framework developed by Ngwenyama and Lyytinen (1997) to categorize the roles played by IT in the Circle County public defender's office. Ngwenyama and Lyytinen propose the following four categories of social action in groupware: instrumental, communicative, discursive, and strategic.

Instrumental action focuses on end results by controlling, manipulating, and transforming physical artifacts, such as case documents. As Elliott and Kling (1997) indicate, the use of computerized legal-research tools is frequently observed among legal professionals. Examples of instrumental action include the attorneys' use of IT for: legal research (e.g., searching the Internet, Lexis-Lexis, and Premise); database research 
(searching the Patio system, which contains criminal records, court procedures, and police reports); and knowledge sharing (e.g., contributing to and searching a shared directory) in order to support legal work practices.

Communicative action has an objective of creating and maintaining shared understanding among members who are engaged in accomplishing the same goal. Example technologies that facilitate communicative action include e-mail and computer conferencing. For communicative action, e-mail is a primary tool that the public defenders in this office use. There are two major categories under communicative action: one-to-one personal communication and news/information sharing.

Discursive action involves "the specification and evaluation of goals, objectives, and action-plans, and the achieving of a rational consensus on values and norms that will guide collaborative action" (Ngwenyama \& Lyytinen, 1997, p. 77). In the Circle County public defender's office, discussion mainly took place on the listserv (pubdef-L) provided by the State Public Defender Council. The listserv pubdef-L was subscribed to by approximately 250 defense attorneys statewide. Approximately twenty percent of the attorneys in the Circle County public defender's office were subscribers. Based on the researcher's interviews, these attorneys reported using pubdef-L to: ask questions; share updates about statutes, judges, and prosecutors; brainstorm strategies; discuss current legal issues; and learn from each other. At the same time, e-mail was also used for communicative action. Discussion through e-mail was personal, while discussions via pubdef-L were shared with all participants. 
Strategic action refers to working with individuals to systematically achieve certain goals. It often involves negotiation and bargaining. Public defenders used strategic action when they used e-mail to negotiate plea agreements with prosecutors.

Table 1 describes IT use in the Circle County public defender’s office based on each of Ngwenyama and Lyytinen (1997)'s categories. The researcher further divided the social action categories into smaller ones called "supported work."

\section{INSERT TABLE 1 ABOUT HERE}

\section{Differences between Younger Attorneys and Experienced Attorneys}

This study found that less experienced attorneys were likely to be more comfortable using computers and communicating online whereas experienced attorneys tended to rely more on people, especially their colleagues; more experienced attorneys seemed to believe that face-to-face interactions were more important and necessary than electronic communication.

This researcher also concluded that e-mail is an important IT tool supporting communicative action in this office. Elizabeth Fox, a major felony attorney, admitted the importance of it: "I could not get by without the e-mail. I don't remember what it was like not to have it. We rely on it so much.”

The major felony attorneys in the Circle County public defender's office frequently use e-mail to communicate with each other. However, they seem to use less email in their interactions with the other office attorneys. Elizabeth said, "As far as within the office it would take so long to write it all down. It's easier to go say, 'Hey, look, you 
got ten minutes, let me bounce this off of you, what do you think?' Much quicker than writing” (personal communication). In order to brainstorm with colleagues, the attorneys seemed to want prompt feedback. In a similar way, Joanne Kent, a major felony attorney, explained the difference between e-mail and face-to-face communication:

The one thing with e-mail is you have to make a concerted effort to do it. When we were together in one building, you are walking down the hall and overhear a conversation ... you might hear something interesting that you might want to listen to or you might have had the case like that a month before or a year before, and you just enter the conversation, "oh, oh, oh, I had a case like that. And this is what we did.” Or what are you gonna do because I couldn't figure out how to do that. So, you have all spontaneous wonderful conversations. E-mail is different because you don't have spontaneous conversations. ... Gina Dean who used to be next door. We used to talk all the time. But oddly enough the division of the floor, we don't anymore. And we don't talk much with e-mail. It has the potential of it. It's not a substitute. (personal communication)

The above comment implies that e-mail might be useful for distributing and exchanging information, but might not be appropriate for brainstorming and having stimulating conversations.

On the other hand, many young attorneys mentioned that whenever the public defenders need to work with each other for the same client, they often communicate via e-mail messages. This can occur when the same client is charged with more than one offense. The following example shows a combination of IT use for instrumental and communicative actions. Since Circle County is located in a large city, the office has a budget, and the willingness to accommodate the creation of a database ("Patio") for the criminal legal system. To the researcher, it appeared that the use of Patio was embedded in the attorneys' work practices. Julie Young, a D felony attorney explained the Patio system: "what we have is a lot of information about cases, about Circle Police Department, Circle County sheriff, police reports, peoples' criminal histories.” The 
attorneys in this office are not necessarily assigned to the same clients when the clients are charged with different offenses. Sometimes a person has cases in two or three different courts with various attorneys. Attorneys are not always informed about their client's other cases. Thus, they use Patio to search criminal records to find out whether other attorneys are representing the same clients.

Another way IT is used for instrumental action among the Circle County attorneys is via a shared directory. Knowledge sharing occurs through use of an electronic directory, which contains every attorney's pleadings and motions so that other attorneys can refer to such documents and use similar filings for different cases. Several attorneys mentioned that this directory was a useful tool. On the other hand, some attorneys mentioned that they did not use the shared directory because they wanted to develop their own documents. The shared directory seemed to be used more frequently by less experienced attorneys. Major felony attorneys mentioned that although they formerly used the shared directory, most had developed their own collection of legal motions over the years. Therefore, the shared directory seemed less pertinent to them. There was some concern that the less experienced attorneys could be trapped into the pitfall of using easily available documents without giving serious consideration to the material. A young attorney said:

you can go in there [the shared directory], and there are lots of motions that everybody in the office has used at one point in time or standard motions. And You just go in and change names and case number. So, you don't have to do a whole new motion. I use that a lot ... It's very handy" (Ann Howard, personal communication).

The easy availability of these shared documents might result in filings that are not wellcrafted. 
In summary, younger attorneys who work in the Misdemeanor/D felony division are inclined to integrate IT well into their work practices to support instrumental, communicative, and discursive actions.

\section{Younger Attorneys, Communities of Practice, and IT Support of Identity Formation}

The other side of the communities of practice equation is identity. In this study, identity formation did not appear to be strongly supported by information technology. Attorneys new to the profession are here the focal point for discussion because they are in the early stages of developing their professional identities.

\section{Younger Attorneys in Communities of Practice}

There exist several different communities of practice within the public defender's office. Due to a lack of office space, the attorneys work in three locations: the less experienced attorneys work in the main office, the more experienced attorneys work in an office one block away, and the juvenile-case attorneys are located in the juvenile justice center. ${ }^{5}$ The physical separation of the first two groups means that less experienced attorneys have less frequent interaction with more experienced attorneys.

Because Circle County has a massive court system (twenty courts including misdemeanor courts, Class D felony courts, major felony courts, a drug court, a drug treatment court, a major case unit which specializes in murder and death penalty cases, and various juvenile courts), the attorneys' roles are more specialized than in other counties within this state. Each attorney is assigned to one court. As a result, specific

\footnotetext{
5 This last division was not included in the study.
} 
attorneys handle only major felony cases, murder and death penalty cases, Class D felony cases, misdemeanor cases, and juvenile cases. When young attorneys, who generally do not have much experience, begin working in the Circle County public defender's office, they usually start in misdemeanor court. After they have more experience and demonstrate serious commitment to, and talent for, a criminal defense career, they can move up to Class D felony court, and eventually to major felony court. This is the normal career ladder for public defenders in this office. The office grew into a large organization between the mid- and late-1990s, when the practicalities of improving the expertise of younger public defenders became increasingly vital to the organization.

As a result of physical separation, one community of practice developed among more experienced attorneys who deal with major felony cases. These public defenders share strong professionalism and seem mutually supported. Other communities of practice developed among less experienced attorneys who deal with less serious offenses, such as misdemeanor and Class D felony cases. Ties between members of the latter groups (misdemeanor/D felony attorneys) do not seem as strong as those between the more experienced attorneys. In an attempt to overcome a sense of isolation felt by some of the less experienced attorneys, the organization has tried different interventions.

However, the invisible social line between these groups does not seem to disappear; indeed, the training director indicated that she felt that the sense of separation was growing ever stronger. In addition to the physical separation of the offices, there appear to be misconceptions between groups, which may be amplified by their physical separation. The training director introduced two gatherings to try to integrate the groups: a regular lunch meeting and a mentoring program. No incentive was offered to support 
these programs; instead, participation relies on each attorney being self-motivated to seek opportunities for professional development. Despite different interventions, all the attorneys interviewed mentioned having difficulty with "forced socialization." This kind of top-down initiative to improve information sharing is often unsuccessful (George et al., 1995). Additionally, the lack of appropriate incentives may contribute to low participation (c.f., Olikowski, 1996).

Although it seems natural to find different communities of practice in almost any professional group, the Circle County public defender's office appears to have a dichotomy between less experienced and more experienced attorneys (see Figure 1). Misdemeanor/D felony attorneys seem to have their own community of practice, even though this is further segmented. As shown in Figure 1, communities of practice among younger attorneys (mainly in the Misdemeanor/D felony division) tend to develop based on which court they work in. Consequently, the communities of practice among less experienced attorneys may not be as strong as the one among major felony attorneys.

\section{INSERT FIGURE 1 ABOUT HERE}

\section{Isolation and Overload}

The researcher speculated that the isolation of less experienced attorneys created a situation in which they must rely on the Internet, internal e-mail, and the listserv more than on learning from experienced attorneys. For example, Julie, a D felony attorney, mentioned:

I don't talk to major felony attorneys. Primarily because they are not here, so I don't have their availability as much. . . Also talked to an appellate attorney about an appeal I was dealing with. Certainly I do talk to people at [the major felony 
division], but it's normally by phone just because physically we are not usually in the same spot.

It appeared that less experienced attorneys face three major problems: lack of access to experienced attorneys, specialization of task assignments, and lack of time to devote to professional development. In terms of the two former points, Lave and Wenger (1990) presented a similar case with a group of meat-cutters. The apprentice butchers worked in a separate place where they were not able to observe journeymen. Marshall, who conducted the original study, stated that "the physical layout of a work setting is an important dimension of learning, since apprentices get a great deal from observing others and being observed" (cited in Lave \& Wenger, p. 78). He also argues that specialization of tasks is not beneficial for either apprentices or journeymen, because this limits learning the full range of tasks.

The public defender's office in Circle County faces a similar situation. When the researcher observed the routine of one $\mathrm{D}$ felony attorney, she realized that the attorney had few opportunities to observe more experienced attorneys (those who handled major felony cases) because he had been assigned to $\mathrm{D}$ felony court where all the cases were of the same type, and all of the attorneys were at the same stage. In other words, the younger attorneys were not given "legitimate peripheral participation" opportunities (Lave \& Wenger, 1991). Because of the lack of interaction with more experienced attorneys, misdemeanor/D felony attorneys may not have many chances to learn what it is like to be a public defender and to develop their professional identities.

The less experienced attorneys have fewer opportunities to observe more experienced attorneys on the job due to work specialization, location isolation, and work overload. The attorneys' work specialization has created an environment where less 
experienced attorneys practice without observing more experienced attorneys and without having opportunities to learn from them. Nonaka and Takeuchi (1997) also emphasized the importance of overlapping work. In western companies, work overlaps tend to be perceived as a waste and are avoided to pursue efficiency. However, having work overlap also creates an environment where employees can learn from each other. The isolated locations in the Circle County public defender's office create a situation in which less experienced attorneys do not naturally socialize with more experienced attorneys. In Vaughan's study (1997), engineers working on the Challenger spacecraft were overscheduled and did not have time to reflect on their work resulting in the 1986 disaster. Although misdemeanor/D felony attorneys are encouraged to observe major felony attorneys' trials ${ }^{6}$, they seemed to be overwhelmed by the number of cases they had to handle. A major attorney commented:

I know they are busy, too. I've done these courts. I know that you are incredibly busy, but if you have any interest ... There are a couple who are good about it, but for the most part, I get the impression that they don't care, or they know everything. I might be wrong. But that's the impression I got.

Only a few less-experienced public defenders sat through major felony trials. Major felony attorneys expressed disappointment about younger attorneys' lack of engagement, while misdemeanor/D felony attorneys mentioned that they do not have time to sit through three day trials because they have already assigned court days, i.e., their compensation was salary-based, and therefore, given their existing caseload, these attorneys had no incentive to attend additional court cases.

\section{Professional Identity among Younger Attorneys}

\footnotetext{
${ }^{6}$ Everyone's trial schedules are announced in advance. Major felony attorneys mentioned that observing more experienced attorneys' trials is one of the best ways to learn.
} 
In the public defender's office, attorneys often learn about their profession by socializing with other attorneys. Attorneys' attitudes toward their profession, that of public defender, differ between the two groups. The major felony attorneys are more dedicated to being public defenders, whereas the majority of the less experienced attorneys are more likely to describe their jobs as "a way to get more experience.” Unfortunately for the attorneys in this study, socialization only seemed to occur among those who were physically located in the same office. To help extend a sense of community among public defenders, computer conferencing tools, such as a listserv, could be used to offer opportunities for socialization. Despite its potential, the existing listserv, pubdef-L, does not appear to be helping participants develop their professional identities as public defenders, although it provides a place for knowledge sharing. The overly task-specific nature of pubdef-L may hinder its ability to support socialization.

For the public defenders in this office, development of professional identity is a paradoxical situation. In order to move up the career ladder, they have to develop a professional identity; yet this is difficult when attorneys are in lower status positions, i.e., misdemeanor/D felony attorneys. However, there are also some successful cases of attorneys who started as misdemeanor/D felony attorneys, then moved up to the major felony division quickly, and were equally promoted to leadership positions. The supervisor of this division mentioned that he looks at an attorney's attitude when he was deciding promotions. Attitude may have mean good self-esteem and a sense of professional identity.

The Circle County public defenders who worked on misdemeanor/D felony cases seemed to have a lack of professional commitment that may come: from a scarcity of 
chances to interact with the senior attorneys who had developed professional identities; from being young in this profession; and also from the work assignments that they have as public defenders.

\section{Younger Attorneys' Heavy Reliance on IT}

Although there are a number of factors that affect the development of public defenders' professional identities, the tendency to rely too much on electronic media in the early stages of their careers may impede whether and when they form professional identities, because this type of knowledge (learning how to develop a professional identity) is difficult to transmit in electronic environments. Misdemeanor/D felony attorneys tend to obtain resources from outside the office, perhaps because of their physical isolation. For example, David said:

there's no training sessions right now for $\mathrm{D}$ felony attorneys because you have your mentor, but like me and Nancy there's no chance to talk because she is too busy. So pretty much [you] just ought to learn for your own, get everything done, that's where Groupwise and pubdef-L and Internet comes into play. Because I can just stay at this place and don't have to do a whole lot, it doesn't take much time to pull it. I just bookmark every page and pull it out to see what came down today. I can check everything in a half hour. And the same thing with the pubdef-L. I get it at home to see what issues are out there, see what new issues are, see if there is any changes in law. At least I know what's going on. It doesn't take a whole lot of time or a whole lot of effort to stay up to date (personal communication).

Even though relying on electronic resources sounds like a wonderful solution, it is doubtful that less experienced attorneys could obtain a sense of professional identity from these remote electronic formats. Although pubdef-L provides information about laws, current issues in the field, feedback, and brainstorming opportunities, it does not seem to support the formation of professional identities among misdemeanor/D felony attorneys. 
Hence, the researcher's assertion is that Computer-Mediated Communication (CMC) does not support professional identity formation among less experienced attorneys in this office. Research on CMC in education reports that the students who use online conferencing tools tend to be too task specific and less social than those who use face-toface communications (Cooney, 1998). The content of the listserv is technical and may not provide opportunities for less experienced attorneys to learn how to be public defenders. Apparently, attorneys do not use CMC to discuss what happened in lost trials, how they could improve their practices, or how to respond when people ask them why they decided to become public defenders despite the low status of the public defender profession. These types of discussions do occur in face-to-face communication.

\section{IT Supports Practice, but Not Identity Formation}

Some IT applications significantly support Circle County public defenders’ work practices. This researcher found that almost all the attorneys in the public defender's office frequently use IT to support instrumental action (such as Lexis-Nexis for research) as well as IT such as e-mail for communicative action and listserv for discursive action. Furthermore, the researcher found that misdemeanor/D felony attorneys tend to use all IT applications more frequently than do major felony attorneys. There appears to be two reasons for this tendency. The first reason is that misdemeanor/D felony attorneys are younger and seem more comfortable with using IT. Second, they are relatively isolated and do not have access to human resources, as in the case of the more experienced attorneys. Other studies on teachers (Selwyn, 2000) and mathematicians (Walsh \& 
Bayma, 1996) found that electronic communication can help reduce isolation among those who tend to be isolated from their peers.

\section{INSERT TABLE 2 ABOUT HERE}

The findings indicate that it is not sufficient to have only the four social actions proposed by Ngwenyama and Lyytinen (1997) in order to describe how IT supports communities of practice. The researcher proposes to expand their framework and add another category called “development of professional identity” (see Table 2). As Wenger (1998) states, communities of practice have two major components: practice and identity. All the social actions in Ngwenyama and Lyytinen are categorized as practice, yet a major component of communities of practice, i.e., identity, is missing from the picture. This proposed framework, shown in Table 2, contains both practice and identity. Unfortunately, it is very difficult to facilitate the latter action with IT.

Some authors (e.g., Huber, 1996; Huseman, 1999; Sharp, 1997) assert that IT can foster organizational learning or communities of practice. However, this researcher observed no support for such a claim in the Circle County public defender's office environment. Gottschalk (1999), who conducted a survey of Norwegian law firms and their IT use for knowledge management, also found that there is no correlation between cooperative culture and IT use for knowledge management. In the current study, misdemeanor/D felony attorneys exhibited a high use of IT for all social actions and formed relatively weak and segmented communities of practice. The major felony 
attorneys used less IT for instrumental and strategic actions and some IT for communicative and discursive actions, and had a strong community of practice. High IT use does not automatically lead to a strong community of practice.

These findings lead to the speculation that the heavy reliance on IT for communicative action may in fact weaken communities of practice, as may be the case with the misdemeanor/D felony attorneys. The high use of IT may create an illusion that IT helps the less experienced public defenders to advance their careers, but it does not seem to help younger attorneys in the development of their professional identities, something that is necessary to carry out their jobs. Some misdemeanor/D felony attorneys tend to overlook the importance of professional socialization which naturally emerges from informal interactions between new and more experienced colleagues. Van Maanen (1973) observed policemen and found it vital for new police officers to learn to become a part of their professional community through apprenticeship and informal interactions. Major felony attorneys tended to prefer to communicate with others via face-to-face communication.

\section{Why IT Does Not Support Identity Formation}

In a community of practice, various types of knowledge may be shared. There are three types of knowledge that the members have to learn: cultural knowledge and two kinds of subject-matter knowledge (see the knowledge typology in Table 3). In some communities of practice, the subject matter changes rapidly, e.g., communities of practice among lawyers or IT professionals, whereas sometimes cultures change rapidly, perhaps because of the high rate of turnovers. The original definition of a community of practice 
by Lave and Wenger (1991) appeared to refer to only static cultural knowledge and subject-matter knowledge because they studied long-lasting communities. However, many recent jobs require the learning of subject matter that frequently changes. Therefore, it is also imperative to address the learning of rapidly changing subject-matter knowledge in communities of practice.

\section{INSERT TABLE 3 ABOUT HERE}

In the current study, cultural knowledge refers to what it is like to be a public defender, mainly their professional identities. Most of the tacit knowledge that is necessary to become a full member of the community of public defenders is embedded in the culture of the public defender's offices. Therefore, younger attorneys learn how to be public defenders by observing more experienced attorneys and by talking with them. As Huseman and Goodman state, "culture is one of the most powerful stores of knowledge" (Huseman \& Goodman, 1999, p. 121).

The researcher further classified subject-matter knowledge as either book knowledge or practical knowledge (see the knowledge typology in Table 3). Book knowledge refers to factual knowledge, such as facts gained by encyclopedic awareness of historical case laws and statutes ${ }^{7}$. In contrast, practical knowledge refers to using the book knowledge in practice; for example, how to use the latest case that an attorney found in Lexis-Nexis in a bench trial. The attorneys have learned most of their

\footnotetext{
${ }^{7}$ Of course, when considering statutes and case law, there is room for interpretation. However, in order to arrive at reasoned interpretations, one needs this book knowledge.
} 
fundamental book knowledge in law school, but they also have to keep learning new book knowledge because criminal laws are rapidly changing. In addition, the attorneys have to learn how to use their book knowledge, which will eventually become practical knowledge.

Cultural knowledge and a part of practical knowledge are tacit. As a result, the main mechanism of learning relies on observing experts. Lave has proposed that culture is "the reproduction of ways of being in the world" (cited in Rival, 1996, p. 164). Along the same lines, Rival illustrates two communities of practice in a school village and a longhouse in the forest and states that "culture is not primarily acquired through the internalization of norms and values, or the transmission of factual information and abstract skills, but through interactive learning” (p. 164). The best way to learn tacit practical knowledge is to observe others, especially more experienced, attorneys and to apply that knowledge in practice. The interaction with other attorneys (socialization) plays a major role in the learning of cultural knowledge. Jacob and Jordan (1996) describe "enculturation" as "a child learning cultural norms and behaviors for the first time” (p. 17). By means of everyday practices and interactions with colleagues, the public defenders share, construct, and obtain cultural knowledge.

On the other hand, a part of practical knowledge and book knowledge are explicit. Therefore, they can be shared through documents and electronic formats, such as messages through a listserv. The researcher speculates that the listserv provides a part of the subject-matter knowledge that is explicit, but fails to provide much cultural knowledge. Whereas pubdef-L served to create a sense of a community among defense attorneys in this state, there are some activities that CMC does not support well, such as 
socialization in task-specified online environments and transmission of tacit knowledge. As discussed earlier, online discussions rarely have off-task behaviors (Cooney, 1998). Off-task talk plays the role of socialization in online discussions in order to create shared meaning. Thus, when people are assigned to a specific task (e.g., discussion of criminal cases or class discussion) and to a certain virtual environment (e.g., pubdef-L or fictionL), they might not use the environment for any other purpose (e.g., socialization or transmission of tacit knowledge).

In terms of transmission of tacit knowledge, Roberts (2000) and Brown and Duguid (1993) both argue that tacit knowledge is difficult to transfer through electronic media, because these tend not to contain rich interpersonal communication and tacit knowledge may not be useful in explicit forms. Nonaka's conversion model (1994) also includes human effort to transfer tacit knowledge to explicit knowledge. In this mode, explicit knowledge can be distributed via technologies once the knowledge goes through an "externalization” process (i.e., conversion of tacit knowledge to explicit knowledge).

\section{Implications of This Study for IT Research}

What can we do to support communities of practice with information technologies? Some IT can be used to bring people together. As an example of a computer-supported cooperative work application, senior scientists at a research institution and a graduate student who is learning to be a researcher at a different university can discuss current issues in science, such as green chemistry, by using video conferencing tools (see Hara, Solomon, Kim, \& Sonnenwald, 2003). This kind of technology can provide an environment for both novice and experienced researchers to 
interact with and learn from each other, thus providing "legitimate peripheral participation” to novices. Furthermore, researchers at different locations can share their concerns and experiences with colleagues at other locations by using online conferencing tools. They can be counselors for each other and collectively solve problems. These exchanges could possibly be beneficial for novices, because the experienced researchers' "tacit knowledge” (Polanyi, 1958) could be more explicitly available to them. Novices might be able to gain contextualized practical knowledge in addition to book knowledge. They can learn how to become a "reflective practitioner" (Schön, 1983) and a full member of a community of practice (Lave \& Wenger, 1991) by observing the conversations of experienced researchers. In addition, whereas Instant Messaging tends to be used mainly for informal conversations (c.f., Nardi, Whittaker, \& Bradner, 2000), it could stimulate spontaneous knowledge sharing. However, as noted earlier, fostering cultural knowledge among the members of such a community would be a challenge in an online environment, and, though technologies have evolved since the data were collected, these same issues present.

More importantly, fostering the environment that encourages knowledge sharing becomes crucial. Desouza (2003) describes the study of an IT company that incorporated game rooms for employees to socialize. After several weeks of hesitation, employees began to use the game rooms to interact with peers and exchange practical knowledge. The company also set up a database for the game rooms. During the twenty weeks of monitoring knowledge contributions to the database, Desouza found an increase in project-based knowledge contributions after the installation of the game rooms. Plaskoff (2003) also notes that one of the critical factors to designing a community of practice is to 
have discussions about what it means to be a part of community, not only a community of practice but also churches, neighborhoods, schools, etc., before people join such a community. These discussions can illuminate the reasons for participating, and people may be more likely to stay in the community. More attention needs to be paid to the design of environments before designing IT tools.

\section{Conclusions}

In this paper, the researcher illustrated different types of communities of practice and the role of IT in supporting work practices and identity formation within the communities. The community of practice among major felony attorneys shows attributes of strong professionalism and mutual support, whereas the communities of practice among misdemeanor/D felony attorneys appeared to be fragmented and limited to those who work in the same courts. The latter communities of practice resembles the community of practice formed by the major felony attorneys in character. Nevertheless, their ties to the larger community appear to be weaker than the one with major felony attorneys. There seem to be different factors that make this community of practice feeble: (1) they do not have immediate access to experienced attorneys (location); (2) they are overwhelmed by the number of cases they handle (overload); (3) the specialization of their tasks creates segregation and often does not allow them to observe more experienced attorneys who handle different types of cases; and (4) they are younger lawyers with limited experience.

The interviews and observations revealed that the public defenders in this office use IT significantly for all of Ngwenyama and Lyytinen's (1997) four social actions except "strategic" (see Table 1). Hence, IT in this office plays a major role in supporting attorneys' work practices and connecting them to each other. On the other hand, IT does 
not seem to help overcome the "invisible line" between the two groups of public defenders. The researcher proposed an additional axis to support communities of practice, that is, to provide support for the development of professional identity (see Table 2). More studies need to be done to examine and validate the proposed framework. In addition, the researcher found that misdemeanor/D felony attorneys have a tendency to rely on using IT for instrumental and communicative actions as a resource more than do major felony attorneys, both because they are more comfortable with technologies and perhaps because they are more isolated. The researcher argues that this tendency also makes the community of practice among misdemeanor/D felony attorneys weaker, although there are other compelling factors that influence less experienced attorneys.

This article provides an empirical study that does not support some of the claims made for IT. The researcher started this article talking about efficiency and effectiveness with IT. The use of the listserv may help less experienced attorneys to be more efficient in their work, but it does not mean that using the listserv is effective in helping to develop their career and professional identities. The concept of communities of practice is rich yet complex, and this study has revealed that high IT use does not necessarily produce a strong community of practice. The researcher speculates that heavy reliance on IT use for communicative action may even weaken ties within a community.

Although these findings emerged from the case of public defenders, the researcher believes that this ethnographic study also sheds light on the role of communities of practice and IT in other professions. Other studies, such as ones of research centers, identify the importance of developing professional identities among scientists (Hara et 
al., 2003; Traweek, 1988). Recognition of how to foster professional identity in a community of practice with IT use should become a focal point for discourse in future studies.

\section{References}

Brown, J. S., \& Duguid, P. (1993). Stolen knowledge. Educational Technology, 33 (3), 10-15.

Brown, J. S., \& Duguid, P. (1996). Organizational learning and communities of practice: Toward a unified view of working, learning, and innovation. In M. D. Cohen \& L. S. Sproull (Eds.), Organizational Learning, (pp. 58-82). Thousand Oaks, CA: Sage.

Brown, J. S., \& Duguid, P. (2000). The social life of information. Boston, MA: Harvard Business School Press.

Cabrera, A., \& Cabrera, E. F. (2002). Knowledge-sharing dilemmas. Organization Studies, 23(5): 678-710.

Connolly, T., Thorn, B.K., and Heminger, A. Discretionary databases as social dilemmas. In W.B.G. Liebrand, D.M. Messick, and H.A.M. Wilke (eds.). Social Dilemmas: theoretical issues and research findings. Pergamon Press Inc, Tarrytown, 1992, pp. 199-208.

Cohen, S. G., \& Bailey, D. E. (1997). What makes teams work: Group effectiveness research from the shop floor to the executive suite. Journal of Management, 23 (3), 239-291. 
Cooney, D. H. (1998). Sharing aspects within Aspects: Real-time collaboration in the high school English classroom. In C. J. Bonk \& K. S. King (Eds.), Electronic collaborators: Learner-centered technologies for literacy, apprenticeship, and discourse, (pp. 263-287). Mahwah, NJ: Lawrence Erlbaum Associates.

Davenport, E. (2001). Knowledge management issues for online organizations: ‘Communities of practice” as an exploratory framework. Journal of Documentation, 57(1), 61-75.

DeSanctis, G., \& Poole, M. S. (1997). Transition in teamwork in new organizational forms, Advances in Group Processes, 14, 157-176.

Desouza, K. C. (2003). Strategic contributions of game rooms to knowledge management: Some preliminary insights. Information \& Management 41(1), 6374.

Eisenhart, M. (1995). The fax, the jazz player, and the self-story teller: How do people organize culture? Anthropology and Education Quarterly, 26 (1), 3-26.

Ekbia, H., \& Hara, N. (in press). Incentive structures for knowledge sharing. In Schwartz, D. G. (Ed.), Encyclopedia of Knowledge Management. Hershey, PA: Idea Group Inc.

Elliott, M., \& Kling, R. (1997). Organizational usability of digital libraries: Case study of legal research in civil and criminal courts. Journal of the American Society for Information Science, 48 (11), 1023-1035.

George, J. F., Iacono, S., \& Kling, R. (1995). Learning in context: Extensively computerized work groups as communities-of-practice. Accounting, Management, and Information Technology, 5(3/4), 185-202. 
Gottschalk, P (1999). Use of IT for knowledge management in law firms. The Journal of Information, Law, and Technology, 3. Retrieved April 12, 2005 from http://www2.warwick.ac.uk/fac/soc/law/elj/jilt/1999_3/gottschalk/

Hara, N. (2000). Social construction of knowledge in professional communities of practice: Tales in courtrooms. Unpublished dissertation. Indiana University.

Hara, N., Solomon, P., Kim, S., Sonnenwald, D. H. (2003). An Emerging View of Scientific Collaboration: Scientists' Perspectives on Collaboration and Factors that Impact Collaboration. Journal of American Society for Information Science \& Technology, 54(10), 954-965.

Holland, D. (1992). How cultural systems become desire: A case study of American romance. In R. D'Andrade \& C. Strauss (Eds.), Human motives and cultural models, (pp. 61-89). NY: Cambridge University Press.

Huber, G. P. (1991). Organizational learning: The contributing processes and the literature. Organization Science, 2(1), 88-115.

Huseman, R. C., \& Goodman, J. P. (1999). Leading with knowledge: The nature of competition in the 21st century. Thousand Oaks, CA: Sage.

Huysman, M. (2002). Knowledge sharing in practice. SAP Design Guild Editions, Edition 5. Retrieved February 8, 2005, from http://www.sapdesignguild.org./editions/edition5/km_mh.asp

Jarvenpaa, S. L., \& Liedner, D. E. (1999). Communication and trust in global virtual teams. Organization Science, 10 (6), 791-815.

Johnson, C. M. (2001). A survey of current research on online communities of practice. Internet and Higher Education, 4, 45-60. 
Kim, A. J. (2000). Community building: secret strategies for successful online communities on the web. Berkley, CA Peachpit Press.

Kling, R., \& Courtright, C. (2004). Group behavior and learning in electronic forums: A socio-technical approach. In S.A. Barab, R. Kling, \& J. H. Gray (Eds.), Designing for virtual communities in the service of learning (pp.91-119). Cambridge: Cambridge University Press.

Kollock, P. (1998). Persuasive communication: Measures to overcome real-life social dilemmas. In W.B.G. Liebrand, D.M.Messick, and H.A.M. Wilke (Eds.), Social dilemmas: Theoretical Issues and Research Findings. New York: Pergammon. pp. 307-318

Krackhardt, D., \& Hanson, J. R. (1993). Informal networks: The company behind the charts. Harvard Business Review, 71(4), 104-112.

Latour, B. (1999). Pandra's hope: Essays on the reality of science studies. Cambridge, MA: Harvard University Press.

Lave, J., \& Wenger, E. (1991). Situated learning: Legitimate peripheral participation. Cambridge: Cambridge University Press.

Lincoln, Y. S., \& Guba, E. G. (1985). Naturalistic inquiry. Beverly Hills, CA: Sage.

Nardi, B. A., Whittaker, S. \& Bradner, E. (2000) "Interaction and Outeraction: Instant messaging in action." In Proceedings of the ACM Conference on ComputerSupported Cooperative Work. New York, ACM Press, pp. 79-88.

Ngwenyama, O. K., \& Lyytinen, K. (1997). Groupware environments as action constitutive resources: A social action framework for analyzing groupware 
technologies. Computer Supported Cooperative Work: The Journal of Collaborative Computing, 6 (1), 71-93.

Nonaka, I. (1994). A dynamic theory of organizational knowledge creation. Organization Science, 5(1), 14-37.

Nonaka, I., \& Takeuchi, H. (1997). A new organizational structure. In L. Prusak (Ed.), Knowledge in organizations, (pp. 99-133). Newton, MA: ButterworthHeinemann.

O’Leary, M., Orlikowski, W., \& Yates, J. (2002). Distributed work over the centuries: Trust and control in the Hudson’s Bay Company, 1670-1826. In P. J. Hinds \& S. Kiesler (eds.), Distributed Work. Cambridge, MA: MIT Press.

Olson, G., \& Olson, J. (2001). Distance matters. Human Computer Interaction, 15, 139179.

Orlikowski, W. J. (1996). Learning from Notes: Organizational issues in groupware implementation. In R. Kling (Ed.), Computerization and controversy: Value conflicts and social choices, (2nd ed., pp. 173-189). San Diego, CA: Academic Press.

Orr, J. E. (1990). Sharing knowledge, celebrating identity: Community memory in a service culture. In D. S. Middleton \& D. Edwards (Eds.), Collective remembering: Memory in society, (pp. 169-189). Beverly Hills, CA: Sage.

Orr, J. E. (1996). Talking about machines: An ethnography of a modern job. Ithaca, NY: Cornell University Press. 
Parsons, T. (1939). The professionals and social structure. Social Forces, 17 (4), 457467.

Plaskoff, J. (2003). Intersubjectivity and community building: Learning to learn organizationally. In M. Easterby-Smith \& M. A. Lyles (Eds.), The Blackwell Handbook of Organizational Learning and Knowledge Management, (pp.161184). Malden, MA: Blackwell Publishing.

Polanyi, M. (1958). Personal knowledge. Chicago, IL: The University of Chicago Press.

Rival, L. (1996). Formal schooling and the production of modern citizens in the eduadorian amazon. In B. A. Levinson, D. E. Foley, \& D. C. Holland (Eds.), The cultural production of the educated person: Critical ethnographies of schooling and local practice, (pp. 153-167). Albany, NY: State University of New York.

Roberts, J. (2000). From know-how to show-how? Questioning the role of information and communication technologies in knowledge transfer. Technology Analysis \& Strategic Management, 12(4), 429-443.

Ruhleder, K., Jordan, B., \& Elmes, M. B. (1996). Wiring the "new organization": Integrating collaborative technologies and team-based work. Paper presented at the Annual Meeting of the Academy of Management.

Schwen, T. M., \& Hara, N. (2004). Community of practice: A metaphor for online design? In S. Barab, R. Kling, \& J. Gray (Eds.). Building Online Communities in the Service of Learning, 154-178. New York: Cambridge University Press.

Selwyn, N. (2000). Creating a “connected” community?: Teachers’ use of an electronic discussion group. Teachers College Record, 102 (4), 750-778. 
Sharp, J. (1997). Community of practice: A review of the literature. Retrieved July 8, 2005, from http://www.tfriend.com/cop-lit.htm

Silverman, D. (1994). Interpreting qualitative data: Methods for analysing talk, text and interaction. London: Sage.

Singer, D. L. (1982). Professional socialization and adult development in graduate professional education. In B. Menson (Ed.), New directions for experiential learning: Building on experiences in adult development, no. 16, (pp. 45-63). San Francisco: Joseey-Bass.

Stake, R. E. (1995). The art of case study research. Thousand Oaks, CA: Sage.

Stewart, T. A. (1996, August, 5). The invisible key to success. Fortune.

Su, J. Z. X. (1992). Sources of influence in preservice teacher socialization. Journal of Education for Teaching, 18 (3), 239-258.

Swan, J., Robertson, M., Newell, S. (2002). Knowledge Management: When will people enter the debate. The Twenty Second IRIS Conference (Information Systems Research Seminar In Scandinavia), 7-10 August, Keuruu, Finland.

Traweek, S. (1988). Beamtimes and lifetimes: The world of high energy physicists. Cambridge, MA: Harvard University Press.

Van Maanen, J. (1973). Observations on the making of policemen. Human Organization, 32 (4), 407-418.

Van Maanen, J., \& Barley, S. R. (1984). Occupational Communities: Cultures and Control in Organizations. Research in Organizational Behavior, 6, 287-365. 
Vaughan, D. (1997). The trickle-down effect: Policy decisions, risky work, and the Challenger tragedy. California Management Review, 39(2), 80-102.

Walsh, J. P., \& Bayma, T. (1996). Computer networks and scientific work. Social Studies of Science, 26, 661-703.

Weedman, J. (1999). Conversation and community: The potential of electronic conferences for creating intellectual proximity in distributed learning environments. Journal of The American Society for Information Science, 50 (10), 907-928.

Wenger, E. (1990). Toward a theory of cultural transparency: Elements of a discourse of the visible and the invisible. Unpublished doctoral dissertation. University of California, Irvine.

Wenger, E. (1998). Communities of practice: Learning, meaning, and identity. Cambridge: Cambridge University Press.

Wenger, E. (2000). Communities of practice: The organizational frontier. Harvard Business Review, 78_(1), 139-145.

Wenger, E., McDermott, R., \& Snyder, W. M. (2002). Cultivating communities of practice: A guide to managing knowledge. Cambridge, MA: Harvard Business School Press. 


\begin{tabular}{lll}
\hline Social Action & Supported Work & Software/Tool \\
\hline Instrumental & Legal research tool & Lexis-Nexis, Premise, Internet \\
\cline { 2 - 3 } & Evidence collection & $\begin{array}{l}\text { Patio (criminal records \& police } \\
\text { reports) }\end{array}$ \\
\cline { 2 - 3 } & Knowledge sharing & Shared directory \\
\hline Communicative & One-to-one, one-to-many & e-mail \\
& communications & \\
\cline { 2 - 3 } & News/Information sharing & e-mail \\
\hline Discursive & Discussion & Pubdef-L (listserv) \\
\hline Strategic & Negotiation w/ prosecutors & e-mail \\
\hline
\end{tabular}

Table 1: Roles of IT in the Public Defender's Office in Circle County ${ }^{8}$

\footnotetext{
${ }^{8}$ Patio and Pubdef-L are pseudonyms.
} 


\begin{tabular}{llll}
\hline $\begin{array}{l}\text { CoP } \\
\text { Framework }\end{array}$ & Social Action & Supported Work & Software/Tool \\
\hline Practice & Instrumental & Legal research tool & $\begin{array}{l}\text { Lexis-Nexis, Premise, } \\
\text { Internet }\end{array}$ \\
\cline { 3 - 4 } & & Evidence collection & $\begin{array}{l}\text { Patio (criminal records } \\
\text { \& police reports) }\end{array}$ \\
\cline { 3 - 4 } & & Knowledge sharing & Shared directory \\
\cline { 3 - 4 } & Communicative & One-to-one, one-to-many & e-mail \\
& & communication & \\
\cline { 3 - 4 } & & News/Information sharing & e-mail \\
\cline { 2 - 4 } & Discursive & Discussion & Pubdef-L (listserv) \\
\cline { 2 - 4 } & Strategic & Negotiation w/ prosecutors & e-mail \\
\hline Identity & Rhetorical & Development of & $\begin{array}{l}\text { Face-to-face } \\
\text { discussions } \\
\end{array}$ \\
& & professional identity & Videoconferencing \\
& & & Instant messaging \\
\hline
\end{tabular}

Table 2: Proposed Roles of IT in the Public Defender's Office in Circle County (modified from Wenger, 1998; and Ngwenyama \& Lyytinen, 1997). 


\begin{tabular}{|l|l|l|}
\hline Professional Identity & Cultural knowledge & \multirow{2}{*}{ Tacit } \\
\hline $\begin{array}{l}\text { Subject-matter } \\
\text { knowledge }\end{array}$ & Practical knowledge & \\
\cline { 2 - 2 } & & \multirow{2}{*}{ Explicit } \\
\cline { 2 - 2 } & Book knowledge & \\
\hline
\end{tabular}

Table 3: Knowledge Typology in Communities of Practice 


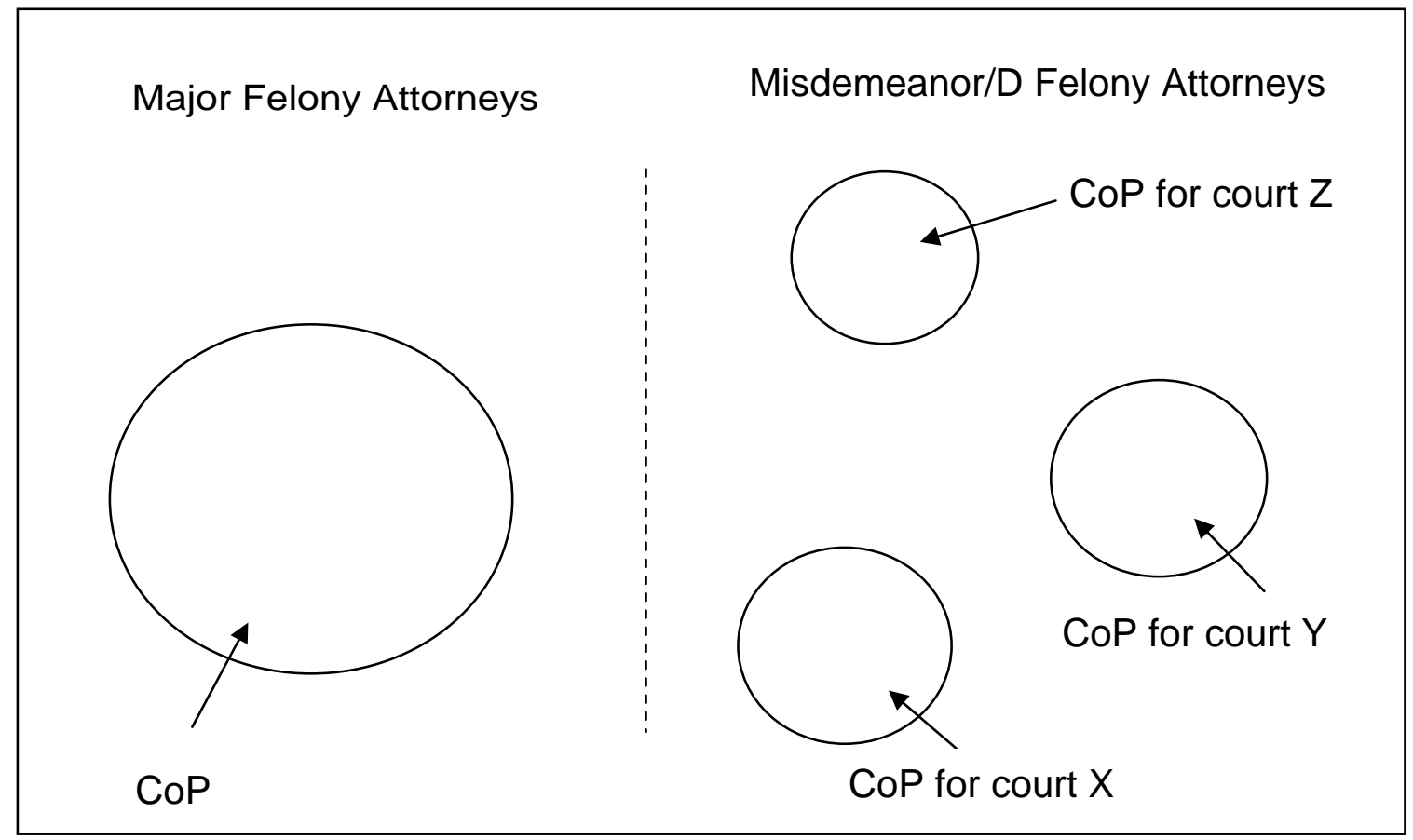

Figure 1. Illustration of Communities of Practice Distribution in the Circle County Public Defender's Office 
Appendix A: Sample Interview Questions for Circle County’s Public Defender’s Office

\section{Interview Questions with attorneys:}

1. How long how you been working in this office?

2. How long have you been practicing law?

3. Could you describe your daily life as a lawyer in this office?

4. How do you collaborate (work) with others in this office?

5. Are there any official learning opportunities? If so, what do you think about them?

6. Are there any informal learning opportunities? If so, what do you think about them?

7. Do you exchange information with your colleagues? If so, how? And what kinds?

8. What kind of tools do you use to work with other attorneys in this office?

9. Is there anything else you want to tell me about your work practice in this office?

10. Is there anything else I should know?

\section{Interview Questions with the Chief Public Defenders}

1. Could you explain to me an overview of this office, such as how many lawyers, workload, who work with whom, etc.

2. What do you want the lawyers in this office to learn from their work practice?

3. What are the issues you have in this office in terms of professional development?

4. To what extent do you think the lawyers in this office exchange their ideas among themselves?

5. To what extent do the attorneys in this office use technologies to communicate with each other? Do you think technologies facilitate the process of learning from each other?

6. What kinds of learning opportunities do you provide?

7. Is there anything else you want to tell me about lawyers' work practices in this office?

8. Is there anything else I should know?

9. How can I contact you if I have more questions? 